\title{
El amor a la patria y a la tribu. Las retóricas de la memoria incómoda
}

\author{
Manuel Gutiérrez Estévez \\ Catedrático de Antropologia Americana \\ da Universidad Complutense - Madrid
}

\begin{abstract}
RESUMO: Se atiende a las emociones y actitudes morales generadas por los himnos nacionales y por cierta clase de poesía indianista, algunos de cuyos textos son comentados desde la perspectiva de una estética de la recepción. Himnos patrióticos y versos tribales constituyen retóricas que construyen sentimientos amorosos diferenciados. Pero, pese a sus diferencias, himnos y poemas elaboran el amor a estas comunidades imaginadas como un instrumento para ocultar o enmascarar la ambigüedad emocional del individuo contemporáneo ante los sujetos colectivos. La patria y la tribu, convertidas en materiales constructivos del yo, se instalan en la intimidad (afectiva) sin dejar de representar, a la vez, a un ello insaciable o menestoroso, según los casos. Sus narrativas son las de una memoria incómoda, la expresión de un malestar en la memoria.
\end{abstract}

PALAVRAS-CHAVE: patria y tribu, himnos nacionales, individuo y sujetos colectivos, memoria

En 1844, un joven hegeliano de izquierdas, Johann Kaspar Schmidt publica, bajo el pseudónimo de Max Stirner, un radical alegato contra el Estado, la religión y la filosofía especulativa con el título de El Unico y su Propiedad (Der Einzige und sein Eigentum). Dice Stirner: "Porque el pueblo no se preocupa más que de mantenerse y de afirmarse, reclama 
de cada uno una [abnegación patriótica]. El individuo en sí le es indiferente, una nada, y el pueblo no debe hacer, ni aun permitir, que el individuo cumpla lo que sólo él es capaz de cumplir, su realización" (1970, p. 155). Las sociedades, los pueblos, organizados con la forma del Estado, ejercen necesariamente, por la propia lógica de su constitución como entes colectivos, una violencia destructiva sobre el individuo, el único ser que, en esta relación, posee, verdaderamente, un cuerpo que le es expropiado y un espíritu que le es inficcionado de sentimientos moralistas.

Vosotros no sois un cuerpo; tú tienes un cuerpo y tú también y aquel tercero igualmente; pero todos vosotros juntos sois cuerpos y no un cuerpo. Por consiguiente, la Sociedad, admitiendo que sea alguien, tendría muchos cuerpos a su servicio, pero no un cuerpo único que le perteneciese en propiedad. Como "la Nación" de los políticos, no es más que un espíritu, un fantasma, y su cuerpo no es más que una apariencia. (1970, p. 95)

Ese fantasma, pese a su incorporeidad, existe multiplicado, reproducido clónicamente en las conciencias de cada uno.

¿Quién no se ha percatado, consciente o inconscientemente, de que toda nuestra educación consiste en injertar en nuestro cerebro ciertos sentimientos [...]? Cuando oímos el nombre de Dios, debemos experimentar temor; cuando se pronuncia ante nosotros el nombre de Su Majestad el Príncipe, debemos sentirnos penetrados de respeto, de veneración y de sumisión; si se nos habla de moralidad, debemos entender alguna cosa inviolable; si se nos habla del mal o de los malvados, no podemos dispensarnos de temblar, y así sucesivamente. Esos sentimientos son obligatorios y quien, por ejemplo, se deleitase en el relato de las hazañas de malvados, sería azotado y castigado para [enderezarlo por el buen camino]. (1970, p. 61-2) 
Pero es preciso añadir que al que se deleita con relatos de malvados no sólo se le castiga, sino que se castiga él mismo sintiéndose culpable. Y la culpa es otro eslabón, quizá el principal eslabón, de la cadena con que se opera la sujeción.

Casi cien años después que Stirner, en 1930, Freud escribe El malestar en la cultura. En las relaciones con la cultura, Freud afirma que "la culpabilidad es la expresión del conflicto de ambivalencia, de la eterna lucha entre Eros y la pulsión de destrucción o de muerte" (1970, p. 74). Creo que donde Freud dice "cultura" puede ponerse, en su lugar, cualquiera de lo que son sus más radicales sinónimos: su rostro institucional como "Estado", su cuerpo pluriforme como "sociedad", su perfil de sujeto histórico como "nación". Como el sentimiento de culpa es la interiorización del conflicto de ambivalencia que está enraizado en el dualismo pulsional, de Eros y Tánatos, de amor y muerte, ese sentimiento de culpa se enmascara, se oculta bajo representaciones que permitan obscurecer la percepción de la ambivalencia. "Así se concibe fácilmente que el sentimiento de culpabilidad, engendrado por la cultura, no se reconozca como tal, sino que permanezca inconsciente en gran parte o se manifieste como un malestar (Unbehagen), un descontento (Unzufriedenheit) que se pretende atribuir a otras motivaciones" (1970, p. 77). Esta artimaña de la cultura es lo que quiere ilustrar Freud al citar como apoyo de su interpretación la famosa frase del monólogo de Hamlet: Thus conscience does make cowards ("Así, la conciencia hace de todos nosotros unos cobardes", según la traducción de Astrana Marín). Pero esta "cobardía" también representa la muerte de la muerte; es la labor del espía que la cultura, trabajando para Eros, ha instalado en el corazón del individuo, para neutralizar los impulsos valerosos y "generosos" que tiene la "guarnición" patriótica que también reside en el corazón como en una ciudad conquistada. 
Es esta "guarnición", instalada en el corazón de los individuos, la que entona himnos patrióticos y recita versos de amor a la tribu. Son estos himnos y estos versos los que vamos a escuchar a continuación. Son himnos y versos de amor y de muerte. Porque el amor a la patria será, simultáneamente, la forma de disimular nuestro malestar, y el modo de ocultar ante nuestros propios ojos la indignidad de esa cobardía nacida de nuestra conciencia moral. Mediante el amor a la patria se transformará la violencia contra nosotros mismos en violencia frente a los enemigos de ella y nuestra sumisión a sus imperativos se convertirá en la heroica valentía de un soldado desconocido. La patria - padre por su raíz etimológica y madre por su género gramatical - reúne, en su peculiar ambigüedad lingüística, la ambigüedad emocional que genera: la resistencia ante sus demandas insaciables y el amor hacia su figura protectora y nutricia.

Si Nairn, según cita Anderson (1993, p. 209), tiene razón al afirmar que es en el fascismo donde se produce la más nítida y fuerte expresividad ideológica y estética del nacionalismo, puedo, como otros muchos españoles de mi generación, mostrar un amplio repertorio de productos educativos nacionalistas. Durante mucho tiempo, después de la última guerra civil española, los niños y adolescentes varones, a partir de los 9 años, debían cursar una asignatura llamada Formación del Espíritu $\mathrm{Na}$ cional. En ella, además de exponer y glosar los principios políticos del partido único, se presentaba el perfil eterno de España y su relación indestructible con el catolicismo. Antes, a los 7 y 8 años, libros de lectura obligatoria iniciaban, con su amenidad narrativa, esa formación conceptual en el nacionalismo; El libro de España y Glorias Imperiales eran los títulos de los que yo leí. También los libros de historia eran concordantes con esta perspectiva. Incluso los de geografía, como por ejemplo: 
El Señor quiere mucho a España.

Por eso la puso en el mejor sitio del mundo, donde no hace ni mucho frío ni mucho calor (Pues en otros sitios o está siempre todo helado o hace tanto calor que no se puede vivir).

Y la colocó entre los mares por los que pasan más barcos: el mar Mediterráneo y el Atlántico.

Y le dió un cielo muy azul, y unos montes muy altos, y unos campos muy grandes y ricos.

¡España es una bendición de Dios!

Los primeros hombres que hubo en España eran leales y valientes.

Vinieron luego otros que eran muy listos: los fenicios; y otros que eran muy sabios: los griegos; y otros que eran muy fuertes: los romanos. Y España era cada día más fuerte y más sabia y más lista. (Sopeña, 1994, p. 164)

Por otra parte, resulta obvio señalar que el canto en común, y muy especialmente el canto ritual, genera un fuerte sentido de co-pertenencia, de comunión. Con una misma voz y con un juicio semejante sobre el valor de lo que se está haciendo, todos los cuerpos que están cantando un himno nacional se unen como si formaran un solo cuerpo con una emoción compartida.

Al cantar el himno nacional se recrean y reproducen las lealtades a un sujeto colectivo, pero el yo, el sujeto individual, no se disuelve magicamente en la nación, sino que experimenta la nación en sí mismo. No importa, como señala Anderson, que las palabras sean enfáticas o triviales y que la música sea pretenciosa o mediocre, para que quienes cantan puedan compartir una experiencia inefable de simultaneidad comunitaria. "Cantando la Marsellesa, la Waltzing Matilda y la Raya indonesia se puede experimentar la consonancia, la realización física de la comu- 
nidad imaginada en forma de eco" (Anderson, 1993, p. 204). Constituye, en este sentido, una acción modélica de funcionalidad ritual; como las expresadas en el Libro de los ritos de Confucio que cita RadcliffeBrown:

Los antiguos reyes se preocupaban de todo aquello que afectaba la mente. Y, así, instituyeron ceremonias para dirigir rectamente los designios de los hombres; música para dar armonía a sus voces; leyes para unificar sus conductas; y castigos para preservarlos de sus tendencias al mal. El fin al que conducen ceremonias, música, castigos y leyes, es el mismo: unir los corazones y establecer el orden. (1974, p. 181)

Pero además de la música, está la letra y la letra es lo que hace "el himno" y lo que permite la participación activa de los compatriotas en la exaltación de su patria. Las letras de los himnos nacionales están en verso y, por su rima, ayudan a la memorización, mientras que, por su ritmo, producen el efecto eufórico característico de la poesía. Pero son versos singulares, para ser cantados en común, y muchas veces con una sintaxis rebuscada, con formas muy poco comunes de hipérbaton que, aunque disminuyen la comprensión, incrementan, en cambio, la sonoridad.

Sin embargo, el himno nacional español sigue sin tener una letra que permita cantarlo colectivamente. Aunque ha habido numerosos textos, incluso irónicos, que se han acompasado a la música de lo que fue, antes, "la marcha real" y es, ahora constitucionalmente, "el himno nacional". Una de esas letras que se difundieron en las escuelas dominadas por el nacionalismo católico decía así:

¡Viva España!, mi Patria esclarecida,

Madre sin igual,

compendio del honor. 
¡Viva España!, solar de noble vida,

regio pedestal

de Cristo Redentor.

Fuiste de glorias florido pensil:

hoy reverdecen a un impulso juvenil.

Veinte naciones coronan tu sien:

¡Arriba España! Raza invicta es tu sostén.

Esas "veinte naciones" que coronan la sien de España son las americanas. Un libro de lecturas escolares sintetiza las relaciones históricas de España y América con estas palabras:

Durante los siglos XVI, XVII y XVIII, todas las naciones americanas de origen español continuaron unidas a la Madre Patria. Después, como hijas casadas, se han ido independizando políticamente. (apud Sopeña, 1994, p. 191-2)

En los himnos nacionales de estas "hijas casadas" que España tuvo, no hay declaraciones de amor filial y sí, en cambio, numerosas proclamas bélicas. Constituyen una glosa enfática y emotiva al mito de origen de cada nación y tienen, por eso, que establecer, con trazos maniqueos, el contraste entre la identidad colectiva emergente y la alteridad que le sirve como referencia. Como se verá enseguida, al comentar los himnos nacionales en América Latina, no son ciertas, en este caso al menos, las afirmaciones de Benedict Anderson (1993, p. 200-1) en el sentido de que "es muy raro el hallazgo de productos nacionalistas que expresen temor y aversión. Incluso en el caso de los pueblos colonizados, que tienen toda la razón para sentir odio hacia sus gobernantes imperialistas, resulta sorprenderte la insignificancia del elemento odio en estas expresiones del sentimiento nacional". Cuando en nota a pie de página, pre- 
gunta Anderson "¿Podría el lector mencionar al instante siquiera tres himnos de odio?", la respuesta que nosotros podríamos darle es "sí y enunciaríamos los himnos de Ecuador, República Dominicana, Perú, Argentina o Cuba. Aunque otros, como el de Panamá o el de Chile ofrezcan la concordia mediante el olvido o el perdón.

Veamos, a continuación, algunas de sus características comenzando por las más aparentes. El vocabulario es, con frecuencia, arcaizante, artificioso, culterano. Numerosos vocablos son de significación totalmente desconocida para la gran mayoría de los hablantes contemporáneos del español.

A esto hay que añadir las referencias mitológicas que se incrustan en algunos textos. Por ejemplo: "cual Rómulo y Remo" (Paraguay); "cual Febo entre nubes" (Paraguay); "la lanza de Marte/de Bruto el puñal" (Uruguay); "Marte mismo parece animar" (Argentina); "centauros indomables/termópilas brotando, constelación de cíclopes" (Colombia).

También se incluyen referencias a héroes y gestas originarias de la nación que son enigmáticas para los extranjeros, pero también para los nacionales con poca escolarización. Por ejemplo: "Del guerrero inmortal de Zempoala te defiende la espada terrible" (México).

Los modos verbales, con abuso de formas subjuntivas y condicionales, refuerzan el estilo arcaizante del texto. Por ejemplo:

Si el extranjero poder algún día

sojuzgar a Bolivia intentare,

al destino fatal se prepare

que amenaza a soberbio agresor.

Este conjunto de características sintácticas, terminológicas, retóricas, no son exclusivas de esta clase de textos, no son las marcas de un género literario formado por los "himnos nacionales" (que tiene otros requisi- 
tos que, más tarde, intentaré especificar). Son rasgos que se manifiestan en otros muchos textos poéticos, aunque no en todos. El resultado es, como tantas otras veces, el de un texto poético que es parcialmente comprensible e incomprensible. Es esta ubicación huidiza, en parte inaprensible, lo que le concede al texto su eficacia; lo que produce la experiencia estética. En mi opinión, el hipérbaton, el vocabulario arcaico, las formas verbales más complejas hacen que el himno sea un discurso que no podemos aprehender,que no podemos hacer, nunca, totalmente nuestro. El resultado es paradójico: el canto que ritualmente nos construye y expresa como un sujeto colectivo, una nación, no es, sin embargo, aprehensible por quienes constituyen ese sujeto.

El concepto durkheimniano de "lo sagrado" parece reflejar bien esta ambigüedad. El himno nacional es nuestro y es, a la vez, de ellos, de los antepasados, de los héroes, de las generaciones anteriores que lo han cantado como nosotros. Su complejidad estilística es el signo de su alteridad, su arcaísmo es la señal de su carácter de emblema histórico. Al cantarlo, no sólo cada uno sale de sí mismo para formar con otros un cuerpo social, sino que cada uno y todos salen de este tiempo para situarse en un tiempo en que el pasado se hace presente y el origen de la nación se revive con las emociones de incertidumbre y decisión que acompañan a un nacimiento. Ese lenguaje de otra época que tiene el himno es el que conviene para hablar de la patria y hablarle a la patria. Porque ella, como eterna que es, no puede ser nunca y totalmente de esta época o de cualquier época. El arcaísmo del lenguaje hímnico no es sólo el que caracteriza a los lenguajes rituales, mantenidos de modo fijo por los que tienen el poder de su administración y uso, sino que es el que corresponde al carácter del objeto al que se refieren.

Por otro lado, hay en los himnos algo que sí se entiende. Hay verbos, adjetivos, substantivos, que son comprendidos por los patriotas que los pronuncian y que tienen una sonoridad fonética que produce emocio- 
nes distintivas. Son palabras sueltas: "lucha”, “extranjero", "opresor”, "libertad”, que a golpes, sin articulación frástica, aparecen periódicamente en el himno. Son las palabras que se entonan con más fuerza vocal y las que producen, también, el sentimiento más fuerte de comunión con los que, a nuestro alrededor, las entonan con semejante vigor. Son palabras que, sin sometimiento a la sintaxis, se unen con otras, anteriores o posteriores en el himno, para formar unas constelaciones de significado literal impreciso pero con sentido emocional claro y diferenciado. Cada una de estas palabras fuertes actúa como un conector con otras análogas para formar esa constelación y, también, como un conector con cada emoción específica que, al final del himno, se articulará con otras para dar como resultado el "amor a la patria". Aunque no tengan la misma importancia, incluso pudiendo alguna no manifestarse en determinado himno, pueden distinguirse cuatro constelaciones emocionales cuyo argumento puede sintetizarse así:

A) Los compatriotas constituyen un "todos" clamoroso, que da voces, que grita al unísono.

B) Los compatriotas constituyen un "nosotros" aguerrido, belicoso, con fuerte agresividad hacia los enemigos de la patria.

C) La patria es un objeto excelso, merecedor de todo amor y de absoluto compromiso de defensa o venganza.

D) El mundo contempla, admira o testifica, el valor de los patriotas y la valía de la patria.

Siguen algunos ejemplos de cada una de estas cuatro constelaciones emocionales.

A) El clamor de los patriotas

$\mathrm{Al}$ comenzar el último tercio de las quince estrofas de que consta el himno de Paraguay, se dice así: 
Compatriotas, ¡el himno entonad!

Suene el grito ¿República o muerte!

Nuestros pechos lo exhalen con fe,

y sus ecos repitan los montes,

cual gigante poniéndose en pie.

La estrofa final del himno de la República Dominicana cita también los ecos de la tierra para gritar, junto con los patriotas, la misma palabra emocionante:

¡Libertad! que los ecos se agiten

mientras llenos de noble ansiedad

nuestros campos de gloria repiten

¡Libertad! ¡Libertad! ¡Libertad!

El himno de Uruguay aclara el porqué de este grito: fue un grito que salvó a la patria y que dio entusiasmo a los soldados. Clamar, gritar, hasta en la muerte, una palabra que se convierte en atributo consubstancial de la patria misma. La libertad de la patria aparece como el máximo bien:

¡Orientales, la patria o la tumba!

¡Libertad, o con gloria morir!

$[\ldots]$

¡Libertad, Libertad, Orientales!

Este grito a la patria salvó,

que a sus bravos en fieras batallas

de entusiasmo sublime inflamó. 
Como corresponde a un concepto tan genérico, las diferencias de clase social no lo afectan y el himno de Venezuela lo expresa así directa y claramente:

[...] abajo cadenas, abajo cadenas,

gritaba el señor, gritaba el señor.

Y el pobre en su choza libertad pidió.

\section{B) Los patriotas belicosos}

La gran mayoría (el 75\%) del corpus de 19 himnos nacionales que estoy comparando, contienen alguna estrofa en la que se presenta a los patriotas que cantan el himno como valientes y aguerridos soldados, llenos de animadversión hacia los enemigos de su patria que, a veces, son enemigos genéricos, pero otras está personificado en España. Por ejemplo, en el himno de Argentina.

El adversario de la patria Argentina, el "altivo león ibérico" se presenta como un sujeto colectivo formado por tigres sedientos de sangre, por fieros tiranos que escupen la hiel apestosa de su envidia y que luego, en su derrota, huyen azorados y cubiertos de infamia.

Los argentinos son interpelados por una voz no definida, pero que parece ser la voz de Dios o la de la historia, quizá coincidentes en una sola voz:

¡Oíd, mortales, el grito sagrado...

¿Quién, si no alguien inmortal, puede dirigirse así a los patriotas? ¿Quién sino Dios, o la historia, puede advertirles así sobre la voracidad de los españoles? 
¿No los veis devorar cual fieras

todo pueblo que logran rendir?

A vosotros se atreve, argentinos,

el orgullo del vil invasor;

vuestros campos ya pisa...

¿Será la voz de la patria encolerizada la que se dirige a sus hijos para enaltecer el heroísmo de que hicieron gala en su defensa? ¿Será la voz de la patria complacida porque el ardor renovado de sus hijos le restaura su antiguo esplendor?

Se conmueven del Inca las tumbas

y en sus huecos revive el ardor,

lo que ve renovado en sus hijos

de la patria el antiguo esplendor.

Los mexicanos, al cantar el himno nacional, también se dirigen a su patria, de forma más explícita que otros, y combinando estrechamente las expresiones de afecto con las declaraciones bélicas.

Mas si osare un extraño enemigo

profanar con su planta tu suelo,

piensa ¡oh Patria querida! que el cielo

un soldado en cada hijo te dio.

En sangrientos combates los viste,

por tu amor palpitando sus senos,

arrostrar la metralla serenos

y la muerte o la gloria buscar. 
Dirigiéndose a Guatemala, su patria, los patriotas guatemaltecos también se refieren al ejemplo dado por sus padres en la lucha y reiteran en cada estrofa las alusiones a la sangre como el icono significativo de su generoso sacrificio.
Nuestros padres lucharon un día
encendidos en patrio ardimiento:
te arrancaron del potro sangriento
$\mathrm{y}$ te alzaron un trono de amor.
[...]
Que tus hijos valientes y altivos
ven con gozo en la ruda pelea
el torrente de sangre que humea
del acero al vibrante chocar.

La herencia de belicosidad y valor que en los himnos de Argentina y Perú se cifra en el Inca y en los de Paraguay y Guatemala, más genéricamente, en "los padres", se hace mitología étnica en el himno de Chile al referirse a la herencia de valor que les ha legado "el altivo araucano" y que se une, en este caso, al poder y coraje que da en la batalla al gritar los nombres de los soldados heroicos que precedieron a los patriotas que, ahora, cantan el himno.

El honor de la patria se defiende con la propia vida y los himnos están haciendo, por eso, contínua referencia a la muerte. Acero, cañones, sangre, guerra, soldados, valor, lucha, muerte, son los términos que una y otra vez aparecen en lo que constituye el núcleo emotivo del himno nacional. Porque es en la lucha como la patria nace y donde se reconoce. 


\section{C) La patria amada y el juramento de su defensa o venganza}

Las declaraciones amorosas hacia la patria toman, con frecuencia en los himnos, la forma de glosas entusiastas a la bandera o al escudo de la nación.

El himno de Uruguay amenaza a quien ofenda la bandera.

¡Orientales, mirad la bandera

de heroísmo fulgente crisol!

Nuestras lanzas defienden su brillo

¡nadie insulte la imagen del sol!

En otros himnos, la patria es aludida por la tierra, el paisaje, la fecundidad de la naturaleza. Como en el himno de Panamá.

En tu suelo cubierto de flores,

a los besos del tibio terral,

terminaron guerreros fragores;

sólo reina el amor fraternal.

Las declaraciones de amor a la patria pueden no limitarse al cielo y al paisaje de la nación, o a la bandera y el escudo, e incluir, también, como en el himno de Honduras, la fantasía de su representación carnal como mujer indígena.

India virgen y hermosa dormías

de tus mares al canto sonoro

cuando echada en tus cuencas de oro,

el audaz navegante te halló.

Y al mirar tu belleza extasiado

al influjo ideal de tu encanto,

la orla azul de tu espléndido manto

con su beso de amor consagró. 
A estas patrias, tan hermosas y dulces, tan amadas, juran defender con valor los patriotas que entonan el himno.

En casi todos los himnos hay juramentos y votos en que se ofrece la vida por la patria. Por muy numerosos y fuertes que sean los enemigos, los patriotas muestran en el himno su determinación; como en el himno de Paraguay:

Contra el mundo, si el mundo se opone,

si intentara su prenda insultar

batallando vengarla sabremos,

¡o abrazados con ella expirar!

El último verso, "abrazados con ella expirar", expresa sintéticamente la fascinación de los patriotas por la íntima relación entre la muerte y el amor a la patria. El juramento a la patria es un juramento de morir por ella.

Este juramento renovado tiene como referencia el que los padres de la patria sellaron con sangre en los orígenes de la nación.

\section{D) La admiración del mundo}

El valor de los patriotas y la excelencia de la patria son reconocidos por el mundo. La relación íntima con la patria, el amor hacia ella, el juramento bélico de su defensa o venganza no produce en otros desconfianza, sino admiración. Así dice el himno de Paraguay:

Con aplauso la Europa y el mundo la saludan, y aclaman también, del heroísmo baluarte invencible, de riquezas magnífico edén. 
El sacrificio de los héroes patrios produce el asombro general y deja al mundo "atónito", como en los himnos de Ecuador y Perú. En el de Ecuador:

Dios miró y aceptó el holocausto,

y esa sangre fue germen fecundo

de otros héroes que, atónito, el mundo

vio en tu torno a millares surgir.

Ella, la patria, tiene nombre. Se llama Argentina, México, Perú... Tiene un nombre propio que se escribe con letra mayúscula, como se escriben los nombres de las gentes de carne y hueso que cada uno conoce o trata, y como se escriben los nombres de las ciudades, los ríos o las montañas. La patria tiene un nombre propio como lo tienen las cosas que son singulares, las cosas que se pueden percibir, tocar, oler o mirar de una forma diferenciada. Aunque nadie conozca el tacto de la patria, ni su olor, ni su rostro, cada patriota la reconoce sin vacilaciones y la ama como a un ser único. La patria tiene una singularidad de naturaleza diferente a la de la nación. La nación es un concepto, mientras la patria es un percepto. La nación puede ser descrita en sus varias dimensiones: por su lengua, por su cultura, por su naturaleza, por su historia, por su configuración social, incluso por su "carácter nacional". Pero, aún la totalidad de las descripciones posibles de la nación, o su elaboración conceptual, no da lugar al percepto de patria. Aunque pueda pensarse que la patria no es sino la expresión sintética y sensible de la nación, su 
doble emotivo, su representación en la sensibilidad, se trata de un sujeto al que la proyección hacia el interior de la conciencia lo ha hecho diferente de su pretexto público, diferente de la nación misma.

Unos versos de Borges expresan esta naturaleza "sobrenacional" (como neologismo paralelo a "sobrenatural") de la patria:

Eres más que tu largo territorio

Y que los días de tu largo tiempo,

Eres más que la suma inconcebible

De tus generaciones. No sabemos

Cómo eres para Dios en el viviente

Seno de los eternos arquetipos,

Pero por ese rostro vislumbrado

Vivimos y morimos y anhelamos,

Oh inseparable y misteriosa patria.

Su rostro, como dice Borges, es un rostro impreciso, misterioso, que sólo se vislumbra y, sin embargo, los himnos nacionales hablan de la patria o, incluso, hablan con ella. Y en ese hablar, en ese discurso, le atribuyen unos rasgos que, aunque a veces parecen contradictorios, dibujan, sin embargo, el perfil de ese objeto que los patriotas anhelan y por el cual dicen vivir y morir. Los rasgos que le atribuyen no son rasgos de la patria, sino que son los rasgos que el amor a la patria sitúa en ella; son los atributos que resultan de la clase de amor que se le tiene, de la clase de amor que la sociedad nacional ha producido hacia su imagen íntima.

Es el amor a la patria el que, mediante su expresión textual, hace tener a la patria un rostro y unos atributos característicos. Identificar esos atributos significa, por tanto, no decir lo que la patria sea (porque nada es), sino hablar de aquellos componentes de un sentimiento socialmente construido (el amor a la patria) que se reproduce, entre otras situacio- 
nes, en el acto ritual de cantar el himno. Hablar de los atributos de la patria no es, no puede ser, sino hablar de la retórica del amor a la patria. La patria, como sujeto discursivamente construido, está configurada, toma su forma, en los textos sonoros y plásticos que reproducen ritualmente el amor hacia ella. La patria está más próxima, es más accesible, a través de sus símbolos (el himno, la bandera, el escudo) que a través de sus pretextos (la nación y sus justificaciones).

Pueden diferenciarse distintos conjuntos de rasgos atribuidos a la patria y, aunque en unos himnos algún conjunto pueda tener más importancia que en otros, en todos ellos se representa la patria con atributos maternales, militares y divinos; complementariamente con rasgos de fecundidad natural o de soberanía política.

La caracterización maternal de la patria es la más obvia y reiterada; hasta el punto de haberse convertido en una locución ya hecha, convencional, la expresión "madre patria". En algunos himnos, los patriotas cuando se dirigen a ella se presentan colectivamente como "tus hijos" (por ejemplo, en los himnos de Costa Rica, México, Ecuador o Guatemala). Esa posición de hijos de la patria llena de orgullo, por ejemplo, a los patriotas de El Salvador ("orgullosos de podernos llamar hijos suyos"), pero al mismo tiempo les obliga, también como hijos, a obedecer a las llamadas o reclamaciones de su madre.

La defensa de la patria no se refiere sólo a la integridad territorial de la nación, sino a la defensa de su honor o de su gloria.

A la patria se le dirige una devoción afectiva que recuerda, en numerosas ocasiones, a la que es normativa en el Mediterráneo dirigir a la madre carnal que está alzada "en un trono de amor", como está Guatemala o que, como Ecuador, es aclamada "por siempre señora". Las expresiones amorosas tienen, a veces, la forma casi de suspiros: ¡oh madre de amor! (Costa Rica) y, con mucha frecuencia, se suceden las galanterías o requiebros como a una mujer amada y se la llama "perla" y se le 
dice "joh cuán pura... dulce" (Paraguay); "amada", "idolatrada", "adorada" (Brasil); "inocente y hermosa" (Bolivia); "dulce", "sin mancha la frente" (Chile); se habla de su "belleza", de su "encanto" o se le asocia con una "india virgen y hermosa" (Honduras); se habla de su "faz" (Guatemala), de su "frente radiosa" que luce "más que el sol" (Ecuador), o de cómo su "pecho rebosa gozo y paz" (Ecuador). Con tanta galantería surge una sensualidad difusa como cuando se dice que es "besado tu suelo por el tibio terral" o "acariciados tus lares, al compás de una canción" (Panamá). La representación de la patria como madre amada permite sentir ansias afectivas como las que quiere producir el himno mexicano al decirle a ella que vió a sus hijos "por tu amor palpitando sus senos".

Pero los atributos femeninos o maternales de la patria están subordinados a sus rasgos militares y, por tanto, viriles. La patria es un "baluarte invencible del heroísmo" (Paraguay), es "indómita", "brava" y tiene "altiva la frente" (República Dominicana), es "noble, constante y valiente" (Chile). Su comportamiento heroico, que se confunde con el de sus hijos, hace que tenga "la frente ornada por los laureles inmortales del triunfo" (México) y que a ella, o la bandera que la representa, se le adjudique el honor y la gloria: "tu glorioso pendón", "tu gloria inmortal", "tu digno laurel", "tu enseña triunfal" (Nicaragua); es "siempre noble" (El Salvador), "ínclita" (Argentina), y eso exige que "su heroico renombre conservemos en glorioso esplendor" (Bolivia).

La patria, esta madre belicosa, tiene, según el sentir de los himnos nacionales, un patrimonio moral y natural que merece todas las alabanzas de los patriotas y permite hacer los mejores augurios de progreso y felicidad para ella. Su principal bien de carácter moral es la libertad y por eso sus hijos no permitirán verla "sierva" (República Dominicana), "esclava ni humillada" (Perú). Su nacimiento ha sido el de la conquista de su libertad "Cesó la horrible Noche - la libertad sublime / derrama las auroras de su invencible luz" (Colombia) y fueron sus padres "los 
padres de la patria" quienes "te arrancaron del potro sangriento" (Guatemala); en ese parto, en que termina la noche y comienza la aurora, la voz de esta madre recién nacida es la voz de la libertad: (“¡Oíd, mortales, el grito sagrado: libertad, libertad, libertad” dice el himno argentino). Así comienza "tu libre existencia" (Ecuador) para realizar "tu noble misión” (Panamá) o "su grandioso destino" (El Salvador) que permitirá hablar de "la patria feliz" (Bolivia), de "Guatemala feliz", de su "libre y feliz pabellón” (Cuba). Los signos sensoriales de esa felicidad están en la tierra y en el cielo de la patria. En la tierra fecunda y, sobre todo, florida; en el cielo puro y limpio. La patria es una "magnífico edén de riquezas" (Paraguay) o, incluso, "la copia feliz del Edén" (Chile). La patria tiene su suelo "cubierto de flores", como en Panamá o en Chile; tiene la tierra "más garrida" donde sus "lindos campos tienen más flores" y "los bosques más vida" como en Brasil. Sobre esa tierra paradisíaca de la patria está "el límpido azul de tu cielo" (Costa Rica) o el "cielo azulado" y "puro" como "puras" son "las brisas" que lo cruzan (Chile).

La patria: una madre amada, heroica, adornada con laureles ganados en batallas donde ha conquistado honor y gloria; la patria: dulce, inocente, cubierta de flores y pura como el azul de su cielo. Ella es situada en el espacio reservado a los dioses y los calificativos que se le dedican son los mismos que a un dios, o a una diosa. Es "la patria deidad" (Paraguay), que tiene un "nombre sagrado" (México) o "inmortal” (Guatemala), un "eterno destino" (México), o un suelo, también "sagrado" (Paraguay) o una gloria, también "inmortal” (Nicaragua). Como corresponde a esta condición divina, tiene sus "aras" (Bolivia, México) y, como otras figuras sagradas, inmortales, eternas, a ella se le consagra el llamado "altar de la patria” (Guatemala). Comparte servidores con el mismo Dios y es "el arcángel divino" quien "ciñe sus sienes" (México).

Esta diosa virginal y guerrera, esta Palas Atenea de múltiples nombres (Argentina, Brasil, México), esta representación discursiva del pue- 
blo al que cada uno pertenece y se debe, es el fruto de un sentimiento amoroso que se complace en pensarse a sí mismo como carente de límites y condiciones. Es el sentimiento que, por su generosidad, eleva a los individuos a la misma condición de nobleza que se adjudica al objeto de su amor, la patria misma. Montesquieu (1984, p. 60), al tratar sobre qué se entiende por virtud en el Estado político, afirma:

El amor a la patria conduce a la pureza de costumbres, y a la inversa, la pureza de costumbres lleva al amor a la patria. En la medida en que podemos satisfacer menos nuestras pasiones particulares, nos entregamos más a las generales. ¿Por qué los monjes tienen tanto cariño a su Orden? Precisamente por lo que tiene de insoportable. Su Regla les priva de todo aquello en que se apoyan las pasiones comunes; así pues, sólo les queda la pasión por la Regla que les aflige. Cuanto más austera es, es decir cuantas más inclinaciones cercena, con más fuerza crecerán las restantes.

Con estas palabras alude Montesquieu a lo que es la raíz del malestar, de la incomodidad profunda de la conciencia y de sus compensaciones placenteras, en el amor a la patria. Como los monjes aman a su Orden por lo que tiene de insoportable, así los patriotas aman a su patria por lo que tiene de exigencia celosa, por el sacrificio que reclama de "nuestras pasiones particulares". Pero es este sacrificio, el que produciendo la imagen ilusoria de nuestra nobleza, lo que genera y moviliza el sentimiento amoroso hacia la patria, como hacia la Regla, la norma, la ley, el deber con que ella se vincula con cada uno de los patriotas. Amor a cambio de sacrificio; éste es el trato con la patria. Así es su doble faz, maternal y belicosa. Mediante el cumplimiento de este trato proporcionará un cielo y una tierra, una pertenencia que permite eludir la noticia sobre la propia muerte. Es por ello, por lo que hay que compadecer al 
hombre a quién no se le haya legado una patria; "a quién se le ha transmitido una patria y aquél en cuyo ánimo penetran cielo y tierra, lo visible y lo invisible, creando de este modo un cielo verdadero y sólido, ése lucha hasta la última gota de su sangre para, a su vez, transmitir íntegramente a sus descendientes la propiedad querida" (Fichte, 1984, p. 162). Cuando esta propiedad se ha perdido, cuando los avatares de la historia colectiva y personal han producido la pérdida de la patria, se busca por todos lados, algo que poder amar de una forma semejante, algo que posea, como dice Fichte, "un cielo verdadero y sólido". Es una búsqueda sin fin. Es la búsqueda que nombra Ernst Jünger al considerar que "cuando hemos perdido el sentido de la patria, buscamos los mundos lejanos que nos ofrece la aventura” (1962, p. 128).

Es sobre este pensar desde el destierro, sobre este sentir nostálgico, sobre el amor a la tribu que ha dejado de ser patria, o que se pretende convertir en patria, sobre lo que voy a hacer unas breves consideraciones tomando como referencia algunas piezas de poesía contemporánea en lenguas indígenas. (Aunque la tribu pueda, en algunos casos, ser considerada como única referencia patriótica, el término lo empleo, en esta ocasión, como un término genérico que incluye a comunidades "naturales" que segmentan el Estado y pueden competir con él por la lealtad de sus miembros. Aludo, por tanto, bajo el término "tribu" a regiones o comarcas con auto-conciencia de singularidad, a grupos étnicos, a conjunto lingüísticos homogéneos, o incluso, a localidades o pueblos).

Es, quizá, en algunos textos escritos en quéchua donde toma forma más expresiva el sentimiento de amor nostálgico hacia la figura de un soberano, el Inca, que es considerado emblema de una patria perdida en la ya lejana conquista española que, sin embargo, se actualiza en su recuerdo dolorido. Como, por ejemplo, en una canción traducida por Adolfo Vienrich: 
¿Dónde está nuestro señor rey del imperio peruano, que hizo un pueblo soberano de los desiertos de horror? Se perdió: ¡Ah qué dolor!

¡Sólo quedan en la memoria recuerdos para la historia de su perdida grandeza, de su proverbial riqueza, de su poder, de su gloria! (1959, p. 107)

Pero, pese a que se diga que la memoria sólo guarda recuerdos para la historia, en otra canción recogida en la misma obra, el Inca es nombrado como si estuviera presente y fundido, como en un monumento patrio, a la fortaleza de Sacsayhuaman, en las afueras del Cuzco.

¡Vamos pronto madre mía!

A nuestra fortaleza de Sacsayhuamán;

allí estará sentado nuestro Inca, con sus cabellos de plata y su corazón de oro.

El Inca emblemático de la patria añorada va y viene, del pasado al presente y del presente al futuro. Son éstos los efectos de una memoria incómoda que pretende reconstruirse mediante ensueños y delirios. Como directamente lo declara un poema procedente de la recopilación de Cosme Ticona, traducido por Arguedas y publicado en Poesía y prosa quechua (1968, p. 47). 
Bajo extraño imperio, aglomerados los martirios, y destruidos;

perplejos, extraviados, negada la memoria,

solos;

muerta la sombra que protege;

lloramos;

sin tener a quién o a dónde volver,

estamos delirando.

El primero de estos versos podría formar parte de un himno nacional, pero luego, los siguientes versos de la estrofa tienen un estilo elegíaco que contrasta grandemente con el triunfal de las patrias constituidas. Pero la elegía no es obligatoria en las condiciones contemporáneas de los pueblos indígenas. Hay poetas que dedican a su patria chica, a su comunidad, elogios que no desmerecen de los que pueden dirigirse a la patria grande. Este es el caso, por ejemplo, de un poema de Juan Gregorio Regino, escrito en mazateco, que forma parte del libro No es eterna la muerte y que, traducido por él mismo al castellano, dice así:

\footnotetext{
A Ixcatlán

Tus hijos te han forjado de trabajo,

de la mística y sobriedad que le heredaste,

del sudor que derramaron los abuelos,

para ponerte de pie como quedaste.

Sobre tu tierra se recoge lluvia,

en el seno de aquel cerro sagrado.

En tus huipiles se escribe historia, arte y memoria de tus mujeres fieles.

Las imponentes torres de tu iglesia, reflejan el linaje de tu gente.
} 
Las lajas que cubren tus calzadas, conservan la huella del pasado.

El generoso río que bañó tus campos, sació la sed del andador sediento.

Las fuerte murallas que rodean tu centro son las montañas y tus valientes hombres.

La enumeración de los motivos que merecen el elogio del pueblo de Ixcatlán no forma parte de la retórica patriótica. A la patria se le nombra más mediante sinécdoques que por la retahíla de sus elementos: el cerro, los huipiles de sus mujeres, las torres de su iglesia, las piedras de sus calzadas, el río, las montañas... Sin embargo, lo que comienza siendo amorosa descripción, termina en enardecida proclama belicosa como si de un himno se tratara. Pero la mezcla resulta disonante, desequilibrada, y convierte en inverosímiles las triunfales afirmaciones de su final: Fuiste verdugo... fuiste trinchera... Es una disonancia semejante a la que utiliza Pessoa para expresar la tendencia hiperbólica del amor local: "El Tajo es más bello que el río que corre por mi aldea. Pero el Tajo no es más bello que el río que corre por mi aldea porque el Tajo no es el río que corre por mi aldea”.

La retórica épica con que se construye el amor a la patria no es fácil trasladarla a otros objetos. Por eso, cuando se trata de amor a la tribu, la fórmula más consistente, la que mejor se acomoda a la memoria de lo que se ha perdido, es la fórmula estilística de la remembranza más o menos dolorida, más o menos esperanzada, más o menos amenazadora de otras patrias.

Natalio Hernández, poeta nahuatl, ha encontrado la manera de amar su sueño de una patria perdida mediante la evocación arcaizante de los restos que la erudición historiográfica ha puesto a su alcance. Canto nuevo de Anahuac, Yancuic Anahuac Cuicatl, se llama su último libro. Uno de sus poemas dice: 
Yo soy Cuauhtemoc:

soy el hombre joven

y el hombre viejo;

conmigo se apagó nuestro Sol

y conmigo nacerá el nuevo Sol.

Los anuncios de una nueva época en la que renacerá la cultura prehispánica son continuos, aunque carentes de la épica apocalíptica que puede, en cambio, apreciarse en algunas muestras de la poesía escrita en quechua. Los versos en nahuatl de Natalio Hernández ponen el énfasis en el valor de una imaginaria "sabiduría” perdida y próxima a recuperarse. Por ejemplo:

No estamos solos

los dioses caminan con nosotros

los guerreros nos fortalecen

recibimos consejos de los ancianos.

Queremos fortalecer nuestras raíces

deseamos fortalecer nuestros corazones

y difundir nuestra sabiduría.

Los sentimientos amorosos construidos por los versos de amor a la tribu carecen del vigor épico de los dedicados a construir el amor a la patria y oscilan entre las expresiones líricas de la nostalgia y de la esperanza. Si la patria es una deidad maternal y belicosa, la tribu, en cambio, es un conjunto heterogéneo de cosas (desde el paisaje a la sabiduría) que cuando se encarna lo hace en una figura masculina (el Inca o Cuauhtemoc) despojada de sus antiguos atributos y poderes militares. El amor a la tribu tiene, así, rasgos que construyen a la tribu misma como a un 
padre vencido por la historia y cuyo recuerdo produce un afecto incómodo, contradictorio.

$\mathrm{Si}$ estos comentarios tienen alguna pertinencia, resultaría que nos encontramos ante dos sujetos colectivos, la patria y la tribu, que son amados de manera diferente, con amores que se construyen mediante retóricas distintas y que producen, también, incomodidades diferentes.

Frye, al referirse a formas temáticas específicas, dice que en el panegírico, que combina las características de la lírica y del epos, "el poeta invita a su lector a contemplar otra cosa en su compañía. Si esta otra cosa no se encuentra visiblemente presente, se nos ofrece el poema de la comunidad, tal como ocurre en el caso de los versos patrióticos de todo género" (1977, p. 391). Y más adelante afirma que "el himno nacional es otra forma que ejemplifica la estrecha relación con el poema comunitario". Según hemos visto en las páginas anteriores, tanto el himno nacional como el poema tribal son, en este sentido, "panegíricos", pero así como el primero es épico-lírico, tanto por la extensión de las estrofas de uno u otro carácter como por el estilo dominante, el segundo, el poema tribal es, en cambio, lírico-épico. Esta diferencia de énfasis en uno u otro registro emocional implica la generación de distintos modos de identificación del cantante o del lector con los respectivos objetos de sus panegíricos. La patria o la tribu, según como sean discursivamente construidas, promueve emociones distintas y, por tanto, procesos identificatorios diferentes.

Desde la perspectiva de la teoría de la recepción, en los himnos nacionales y los poemas tribales, la emoción caracterizada, demasiado genéricamente, como "amor", sea a la patria o a la tribu, debe ser, ahora, contextualizada por la relación recíproca entre cada sujeto y objeto de ese "amor". Para ello utilizaré la tipología de los modelos interactivos de identificación con el héroe elaborada por Jauss (1986) y que modifica la anteriormente establecida, con una perspectiva historicista, por Frye. 
Jauss distingue cinco tipos de identificación: asociativa, admirativa, simpatética, catártica e irónica. En mi opinión, en el amor a la patria, construido por los himnos nacionales, se da una identificación asociativa con el héroe, es decir la patria misma; mientras que en el amor a la tribu, generado y reproducido por la poesía tribal, se produce una identificación que oscila entre la admirativa y la simpatética.

La identificación asociativa, característica del himno nacional, implica la movilización emocional del sujeto hacia el comportamiento estético colectivo que caracteriza tanto al juego como a la celebración y al ritual. La praxis estética del himno nacional exige su realización colectiva y la sujeción a unas normas específicas de control gestual y postural. La composición poético-musical que es un himno se recibe en público y con sujeción a un rol de actuación. Cada sujeto es intercambiable con los otros y en esa virtualidad de intercambio se produce no sólo la asociación de todos los patriotas entre sí, sino también la de cada uno de ellos con la patria cantada.

El poema tribal, como he dicho hace un momento, oscila pendularmente entre la identificación admirativa y la simpatética. Según Jauss,

por identificación admirativa entendemos la actitud estética que se origina ante la perfección de un modelo que queda más allá de la separación del efecto trágico o cómico (...), lo que convierte la admiración en emoción estética que dispone al reconocimiento y asunción de ejemplos y modelos, no es el mero asombrarse por lo extraordinario o lo perfecto, sin el acto-distanciador, en el que la conciencia echa de menos su asombro por el objeto. (1986)

La tribu representa, en el poema tribal, un modelo de sabiduría, de equidad, de piedad y, en ocasiones, de poder y de riqueza. Ese modelo despierta el asombro de lo otro aunque no puedan especificarse, o al 
menos aunque no se especifiquen, los rasgos de esa alteridad. No se dice cómo ni porqué era distinta la piedad que se dirigía a los antiguos dioses tribales que la que, ahora, se rinde a los nuevos dioses universales. Pero, sin embargo, esa sabiduría o esa piedad que se canta en el poema tribal es admirada y añorada. Al mismo tiempo, o en vaivén, se produce, como he dicho, una identificación simpatética. Según Jauss, por identificación simpatética "entendemos la emoción estética consistente en ponerse en el lugar del yo ajeno. Lo que suprime la distancia admirativa y lleva al lector o al espectador a solidarizarse, a través de la emoción, con el héroe sufriente. La praxis de la experiencia estética prueba cómo la admiración y la compasión entran en una relación de consecuencia”. Así lo vemos, desde luego, en el poema tribal.

De otra parte, por medio de la identificación asociativa, cada uno, cada patriota que canta el himno nacional, se siente co-partícipe de la gloria y el honor de su patria. Su participación en estos bienes morales está legitimada y asegurada o garantizada por el amor filial que tiene hacia ella. Por otro lado, cada uno de los patriotas está asociado, unido, con todos los demás en su identificación con la patria. Se produce una depreciación del ego(-ismo) y una sobrevaloraciónn inversa del nosotros constitutivo de la nación. Ante la patria, en el amor asociativo hacia ella, son tan eternos e inmortales como ella, tan invencibles como ella (invencibles ante las agresiones de los otros y ante las agresiones del tiempo). Con esta fantasía los patriotas se cobran lo que han sacrificado ante el altar de la patria: el interés individual, la inteligencia crítica, la autonomía emocional. Pero, cada vez que cantan el himno y renuevan el contrato patriótico, recuerdan oscuramente las cláusulas del contrato y este recuerdo produce incomodidad por la sospecha ineludible de que, por un lado, el contrato no es libre (no hay disculpa para el traidor) y, por otro, porque sus estipulaciones no son equitativas (se ha comprado fantasía o ilusión con el sacrificio de la libertad y el deseo). 
En la identificación admirativa y simpatética con la tribu, cada uno se siente capaz de sentimientos desinteresados que no implican sacrificio. Cada lector de poesía tribal admira, compadece y ama a su tribu, pero no se ve obligado a declarar su disposición a defenderla; tan sólo, quizá, a no negarle su adhesión nominal. Pero esas emociones, en apariencia desinteresadas, de admiración y compasión, constituyen un ejercicio de masoquismo sentimental. Porque, al admirar y compadecer simultáneamente a ese yo ajeno que es la tribu, cada lector se admira y se compadece de sí mismo, convirtiéndose imaginariamente en una víctima injusta y noble. Amando a la tribu, a la patria perdida, cada uno ama su propia pérdida, su propia insignificancia y se reconcilia con ella. Es la percepción de la injusticia cometida con la tribu, el que, pese a ser tan legítimamente admirada, tenga que ser compadecida, lo que produce, en este caso, la incomodidad en la memoria. Una incomodidad acentuada por el compromiso moral que implica. Hay que ser digno de la tribu antigua, de la patria desaparecida, para que así, con el esfuerzo de cada uno, renazca, como un nuevo sol, en su esplendor. Mientras que las virtudes de la patria se comparten automáticamente por los patriotas, las virtudes de la tribu se alcanzan mediante la emulación, el celo moralizador. Cada vez que se lee el poema tribal, como cada vez que se canta el himno nacional, se renueva un compromiso moral, ahora con la tribu, y se recuerda, en algún lugar de la conciencia, la incomodidad de la situación. No es, en este caso, una incomodidad análoga a la sugerida por el contrato patriótico, porque, en esta ocasión, la incomodidad procede de la actualización del estado mismo de la tribu, de su postración, de la postración de cada uno de los lectores identificados con ella. El amor hacia ella, como el amor a la patria, atenúa esa incomodidad. Pero la incomodidad nace, también de ese mismo amor, es su secuela; y es ese amor el que hace a todos,nos hace a todos, víctimas del sueño. 
Manuel Gutiérrez Estévez. El amor a la patria y a la tribu...

\section{Bibliografia}

ANDERSON, B.

1993 Comunidades imaginadas, México, F.C.E.

BORGES, J. L.

1966 "Oda compuesta en 1960", in Obra Poética, Buenos Aires, Emecé.

CARRILLO, F. (sel.)

1968 Poesía y prosa Quechua, 2a. ed., Lima, Biblioteca Universitaria.

FICHTE, J. G.

1984 "Qué es un pueblo en el sentido superior de la palabra y qué es amor a la patria”, in Discursos a la nación alemana, Barcelona, Orbis.

FREUD, S.

1970 El malestar en la cultura, Madrid, Alianza Editorial.

FRYE, N.

1977 Anatomía de la crítica, Caracas, Monte Avila.

HERNÁNDEZ, N.

1994 Canto nuevo de Anahuac, Yancuic Anahuac Cuicatl, México, Diana.

JAUSS, H. R.

1986 Experiencia estética y hermenéutica literaria, Madrid, Taurus.

JUNGER, E.

1962 Sobre los acantilados de mármol, Barcelona, Destino.

MONTESQUIEU.

1984 Del espiritu de las leyes, Barcelona, Orbis.

NAIRN, T.

1977 The Break-up of Britain, Londres, New Left Books. 
RADCLIFFE-BROWN, A. R.

1974 Estructura y función en la sociedad primitiva, Barcelona, Península.

REGINO, J. G.

$1994 \quad$ No es eterna la muerte, Tatsjejin nga kjabuya, México, Diana.

SOPEÑA, A.

1994 El florido pensil. Memoria de la escuela nacionalcatólica, Barcelona, Crítica.

STIRNER, M.

1970 El único y su propiedad, Barcelona, Mateu.

VIENRICH, A.

1959

Azucenas Quechuas: Nuna-Shimi Chihuanhuai, Tarma, Consejo Provincial.

\begin{abstract}
Attention is directed to moral attitudes and emotions generated by national anthems and by a certain category of Indianist poetry, with commentary being made on a selection of texts from the perspective of an aesthetic of reception. Patriotic anthems and tribal verses constitute rhetorics which construct differentiated amorous sentiments. However, notwithstanding the specificity of different forms of expression, anthems and poems elaborate the love for imaginary communities as an instrument for concealing or disguising emotional ambiguity of the contemporary individual in the face of collective subjects. Country and tribe, when converted into building materials of self, become part of (affective) intimacy even as they represent an insatiable or necessary other, as may be the case. Such narratives arise from a troubling memory, as the expression of memory's discomfort.
\end{abstract}

KEY-WORDS: country and tribe, national anthems, individual and collective subjects, memory 